\title{
Глобальное и региональное сотрудничество государств в области защиты беженцев
}

\author{
Иванов Д.В.*
}

Международное сотрудничество государств в области защиты беженцев осушествляется не только на универсальном уровне, как в случае с УВКБ ООН, но и на региональном уровне. Региональное сотрудничество, с одной стороны, позволяет продублировать или прямо или косвенно содействовать выполнению положений универсальных международных соглашений, касаюшихся зашиты беженцев, а с другой разработать и заключить региональные документы по данной проблематике, которые будут учитывать политические, экономические, правовые и другие особенности определенного региона при решении проблем беженцев.

В настояшее время в каждом регионе сушествует региональная система сотрудничества по вопросу защиты беженцев в форме создаваемых региональных международных организаций и заключаемых в их рамках международных договоров. Таковы следующие региональные организации: Африканский союз, Организация американских государств (ОАГ), Совет Европы, Содружество независимых государств (СНГ), Организация по безопасности и сотрудничеству в Европе (ОБСЕ) и ряд других. Среди документов, принятых государствами участниками данных международных организаций, нужно выделить следующие: Конвенцию ОАЕ 1969 г., регулирующую конкретные аспекты проблемы беженцев в Африке', Американскую конвенцию 1969 г. о правах человека ${ }^{2}$, Европейскую конвенцию 1950 г. о зашите прав человека и основных свобод ${ }^{3}$, Соглашение о помощи беженцам и

\footnotetext{
- Иванов Дмитрий Владимирович - к.ю.н., доцент кафедры международного права МГИМО (У) МИД России.

' Вступила в силу 20 июня 1974 г. По состоянию на 31 января 2001 г. в конвенции участвовало 42 государства.

2 Вступила в силу 18 нюля 1978 г.

' Вступила в силу 3 сентября 1953 г. По состоянию на 31 января 2001 г. в конвенции участвовало 40 государств.
} 


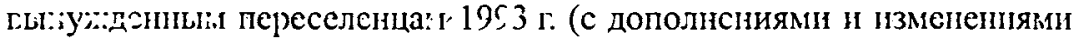
от 1995 г.) $)^{4}$ и др.

Необходимость межорганизационного и межгосударственного сотрудничества в вопросах защиты беженцев и других категорий вынужденных мигрантов все чаще рассматривается на многочисленных конференциях и форумах. В данной статье будет рассмотрено сотрудничество государств в рамках межрегиональных организаций и конференций.

Проблема беженцев всегда была актуальна для африканского континента, положение в странах которого в настоящее времл характеризуется политической и экономической нестабильностьо, а также многочисленными и кровопролитными вооруженными конфликтами немеждународного характера на национальной или политической основе ${ }^{5}$.

Во многих африканских государствах законодательство вообще никак не регулирует правовое положение беженцев. Причина тому - отпошение к проблеме беженцев как к временной по своему характеру. Российский ученый В.И. Потапов полагает, что такое положение объясняется тем, что правительства африканских стран не имеют возможности оказывать беженцам необходимую материальную и финансовуго помощь ${ }^{6}$.

В конце 60-х годов XX столетия в рамках Организации африканского единства была принята Конвенция ОАЕ 1969 г., регулиругщая конкретные аспекты проблемы беженцев в Африке. Подписанию этого документа предшествовала большая подготовительная работа7 .

Основной отличительной особенностью данной конвенции является расширительное определение понятия «беженец», сформулированное в ст. 1 данного международного договора. Оно было дополнено новыми обстоятельствами, вынуждаюшими лицо стать беженцем: «вне-

\footnotetext{
${ }^{4}$ Вступило в силу 1 сентября 1994 г. Россия ратифицировала Соглашение 22 ноября 1994 г. Текст Соглашения см.: Действуюшее международное право // Составители Ю.М. Колосов, Э.С. Кривчикова. М., 1996. Т. 1. С. 334.

${ }^{5}$ По данным УВКБ количество лиц, которым он оказывает защиту или помощь на территорин африканского континента, составляет в настоящее время более 7 млн. человек. Основные страны происхождения беженцев - Сомали, Бурунди, Либерия, Сьерра-Леоне, Судан.

'Подробнее см.: В.И. Потапов. Беженцы и международное право. М., 1986. С. 77-78.

${ }^{7}$ Текст конвенции был разработан иа состоявшейся в Аддис-Абебе конференции по правовым, экономическим и социальным аспсктам проблсмы африканских беженцсв.
} 
шняя агрессия, оккупация, иностранное господство или события, серьезно нарушаюшие публичный порядок как в определенной части, так и во всей стране происхождения или гражданства данного лица».

Важным является и тот факт, что в конвенции признается необходимость гуманитарного подхода к проблеме беженцев. В ней указывается, что предоставление убежища является мирным и гуманитарным актом и не рассматривается как недружественный акт со стороны какого-либо государства - члена Африканского союза.

Важным результатом регионального сотрудничества в Африке явилось создание Африканской комиссии по правам человека и народов, собирающейся на закрытые заседания и рассматривающей сообщения о грубых нарушениях прав человека. Создание подобного регионального контрольного органа за соблюдением договоров, касающихся прав человека, способствует выполнению странами региона положений международных соглашений по правам человека и беженцев. Помимо этого контрольного органа, контролем за соблюдением норм международных соглашений занимается непосредственно Африканский союз.

Дальнейшим этапом на пути развития сотрудничества африканских государств стало проведение в мае 1979 г. в г. Аруше (Танзания), Панафриканской конференции. Конференция рассмотрела широкий спектр вопросов, связанных с проблемой беженцев. Среди них - определение статуса беженцев, определение понятия "беженец", правовое положение беженцев и ряд других.

На конференции было подчеркнуто, что принцип невысылки имеет важное значение в решении проблемы беженцев. Этот принцип рассматривается как норма международного права, зафиксированная в Конвенции о статусе беженцев 1951 г., Протоколе к ней 1967 г. и других соглашениях. Несоблюдение этого принципа часто ведет к гибели беженцев.

Конференция рассмотрела вопрос передвижения беженцев в пределах территории государства убежища, а также за его пределы. Этот вопрос и поныне носит актуальный характер, так как законодательства некоторых государств Африки ограничивают свободу передвижения беженцев по своей территории. Конференция приняла решение, направленное на приведение национального законодательства в соответствие с международным правом.

На конференции в Аруше было отмечено, что одним из способов решения проблемы беженцев является их добровольная репатриация 
в страну происхождения. Впервые понятие добровольной репатриации применительно к африканскому континенту было сформулировано в Конвенции ОАЕ 1969 г. в виде отдельной статьи. В ней говорится, что страна убежища в сотрудничестве со страной происхождения принимаег соответствующие меры для безопасного возвращения беженцев, обращающихся с просьбой о репатриации. Проблема добровольной репатриации по-прежнему имеет особое значение для африканских государств. Совместно с УВКБ ООН они осушествляют широкомасштабные программы добровольной репатриации.

Особо следует выделить результаты работы Симпозиума по беженцам и вынужденному перемещению населения в Африке, проведенного под эгидой Африканского союза и УВКБ ООН в Аддис-Абебе (Эфиопия) 8-10 сентября 1994 г. В работе симпозиума приняли участие почти все государства - члены Африканского союза, некоторые государства - члены Исполкома по программе Верховного комиссара $\mathrm{OOH}$ по делам беженцев, представители учреждений системы $\mathrm{OOH}$, международных и неправительственных организаций, а также ученые из многих стран.

В ходе работы симпозиума его участники сформулировали ряд рекомендаций в сфере зациты беженцев. Среди них необходимо выделить:

- государства - члены Африканского союза должны тесно сотрудничать между собой, а также с международными организациями, занимающимися защитой беженцев;

- Африканский союз должен играть все более активную роль не только в решении проблем беженцев, но и в превентивном разрешении причин, вызывающих огромные потоки беженцев;

- все государства должны строго соблюдать положения универсальных и региональных соглашений, касающихся беженцев ${ }^{8}$;

- государства-доноры, международные и неправительственные организации должны оказывать финансовую, материальную и техническую помощь тем государствам, которые испытывают наибольший наплыв беженцев;

- добровольная репатриация беженцев в страну происхождения остается наилучшим решением проблемы беженцев;

${ }^{8} 45$ государств Африки присоединились к Конвенции 1951 г., 46 - к Протоколу 1967 года, 42 - к Конвенции ОАЕ 1969 г. Только 4 государства не присоединились ни к одному из вышеуказанных международно-правовых документов. 
- государства - члены Африканского союза должны оказывать по-, мощь не только беженцам по смыслу международных соглашений, но и другим категориям населения, включая жертв стихийных бедствий.

Участники симпозиума приняли 34 рекомендации по вопросам миграции населения и решения проблем беженцев и перемешенных лиц 9 . Рекомендации симпозиума были одобрены на 45-й сессии Исполкома по Программе Верховного комиссара ${ }^{10}$.

Участники симпозиума отметили прогрессивную роль, которую сыграла и играет региональная Конвенция ОАЕ 1969 г. в деле защиты беженцев и перемещенных лиц. Было выражено мнение, что данное соглашение послужит базой для дальнейшего создания и совершенствования институтов и правовых механизмов зашиты указанных категорий лиц.

Распад СССР, образование на его территории новых независимых государств, ухудшение политической и экономической обстановки в республиках бывшего СССР, начало вооруженных конфликтов вызвали массовые потоки беженцев в этом регионе. Начиная с 1989 г. внутри стран СНГ и между ними переместилось более 10 млн. человек каждый тридцатый житель региона" ${ }^{11}$ В 1991 г., когда распался Советский Союз, общее число людей, живших за пределами своих «родных» республик или автономных областей, составляло от 54 млн. до 65 млн. человек, или пятую часть общей численности населения. Все это способствовало началу активного регионального сотрудничества новых государств по решению проблем беженцев в рамках созданного в 1991 г. Содружества Независимых Государств и его институтов.

С целью решения проблем беженцев в рамках Содружества 24 сентября 1993 г. семь государств - членов СНГ ${ }^{12}$ подписали в Москве Соглашение о помоши беженцам и вынужденным переселенцам, дополненное 10 февраля 1995 г.

Соглашение содержит определение понятия «беженец», совпадающее с определением ст. I Конвенции 1951 г. о статусе беженцев. Одна-

${ }^{9}$ Подробнее см.: The Addis Ababa Document on Refugees and Forced Population Displacements in Africa.

${ }^{10}$ CM.: Report of the Forty-Fifth Session of the Executive Committee of the High Commissioner's Programme, Geneva, 3-7 October 1994, Doc. A/AC.96/839.

11 Эти данные получены в результате исследований, проведенных в ходе подготовки к международной конференции по странам СНГ, состоявшейся в Женеве в мае 1996 г.

${ }^{12}$ Соглашение подписали: Азербайджан, Армения, Беларусь, Казахстан, Кыргызстан, Российская Федерация, Таджикистан, Туркменистан, Узбекистан. 
ко Соглашение дало рождение новой международно-правовой категории - «вынужденный переселенец». В соответствии со ст. 2 Соглашения 1993 г. «вынужденным переселенцем признается лицо, которое, являясь гражданином Стороны, предоставившей убежище, было вынуждено покинуть место своего постоянного жительства на территории другой Стороны вследствие совершенного в отношении него или членов его семьи насилия или преследования в иных формах, либо реальной опасности подвергнуться преследованию по признаку расовой или национальной принадлежности, вероисповедания, языка, политических убеждений, а также принадлежности к определенной социальной группе в связи с вооруженными и межнациональными конфликтами».

Помимо этого Соглашение регулирует следуюшие вопросы: обязательства государств-участников друг перед другом, перед беженцами, создание Межгосударственного фонда помощи беженцам и вынужденным переселенцам, содействие Консультативного Совета по труду, миграции и социальной зашите населения государств - участников СНГ, права беженцев и т.д.

При характеристике этого Соглашения необходимо отметить, что оно носит декларативный характер, так как в нем не предусмотрены ни механизм контроля за исполнением положений соглашения, ни механизм ответственности государств-участников соглашения. Все это, по сути, превращает данный документ в очередное заявление о намерениях, а не в эффективный документ о сотрудничестве.

Соглашение также не учитывает новых тенденций в оказании помощи не только беженцам по смыслу Конвенции 1951 г., но и другим категориям населения, которые получили определение «лица, нуждающиеся в международной помощи».

Во исполнение ст. 8 Соглашения 1993 г. семь государств - участников СНГ 10 февраля 1995 г. приняли решение о создании Межгосударственного фонда помоши беженцам и вынужденным переселенцам. В соответствии с Положением о Фонде его основными задачами являются: аккумулирование финансовых и материальных средств для оказания помощи вышеуказанным категориям населения; распределение средств между государствами - участниками Соглашения, принимающими беженцев и вынужденных переселенцев, в целях организации их переселения и обустройства; содействие государственным органам и общественным организациям в защите гражданских, экономичес- 
ких и социальных прав беженцев и вынужденных переселенцев, а также пропаганда идей милосердия, справедливости, привлечения внимания общественности к проблемам данных категорий лиц.

Фонд состоит из учредителей и членов Фонда. Учредителями являются государства - участники Соглашения, которые обязаны своевременно вносить установленные взносы в бюджет Фонда и активно содействовать выполнению его задач и функций. Учредители имеют право через своих полномочных представителей вносить на рассмотрение руководящих органов Фонда предложения по вопросам, входящим в круг деятельности Фонда, и участвовать в их обсуждении; участвовать в разработке программ оказания помоши беженцам и вынужденным переселенцам; участвовать в распределении средств Фонда.

Членами Фонда могут быть юридические и физические лица, общественные организации. Члены Фонда вносят взносы либо оказывают Фонду содействие друтими материальными средствами.

Высшим органом Фонда является Административный совет, в который входят по одному представителю от государств - участников Соглашения 1993 г. и председатель Исполнительного комитета Фонда. Административный совет собирается на совешания два раза в год. В его обязанности входит определение размеров ассигнований, направляемых на решение задач Фонда; подготовка Совету глав правительств СНГ предложений о размерах ежегодных взносов в Фонд; утверждение персонального состава Исполкома Фонда; утверждение структуры Фонда и др.

Исполнительный комитет Фонда является постоянно действующим и распорядительным органом Фонда. В его состав входят председатель, его заместитель и руководители подразделений Фонда. Исполком подготавливает вопросы, относящиеся к компетенции Административного совета Фонда, и представляет их на его рассмотрение; поддерживает отношения с правительственными органами, неправительственными и международными организациями, частными лицами по вопросам деятельности Фонда; решает текущие вопросы его деятельности.

Однако один Фонд не может решить проблем беженцев и вынужденных переселенцев на территории стран - участниц Соглашения и СНГ. Да и сам Фонд сталкивается с определенными проблемами в своей деятельности. По мнению экспертов, противоречивость интересов стран - участниц Соглашения 1993 г,, принимающих беженцев и вы- 
нужденных переселенцев, (с одной стороны) и государств происхождения (с другой) при непроработанности механизма поступления средств в Фонд и отсутствии санкций способны заблокировать деятельность Фонда. Прибавьте сюда и тот факт, что в Фонде участвуют только семь государств - участников СНГ. Значит, беженцы и вынужденные переселенцы из других государств - членов СНГ не смогут воспользоваться помощью Фонда ${ }^{13}$.

Еще одна проблема, которая может возникнуть в процессе деятельности Фонда, заключается в круге лиц, подпадающих под сферу его деятельности. Согласно Положению о Фонде, его деятельность распространяется только на беженцев и вынужденных переселенцев, пересекающих государственные границы стран Содружества. За бортом оказались другие категории вынужденных мигрантов и лица, нуждающиеся в международной помощи, которым в настоящее время УВКБ ООН оказывает необходимые защиту и помощь.

В рамках СНГ было разработано еще несколько международно-правовых документов, касающихся беженцев. Среди них - Соглашение о первоочередных мерах по защите жертв вооруженных конфликтов от 24 сентября 1993 г., Соглашение по вопросам, связанным с восстановлением прав депортированных лиц, национальных меньшинств и народов от 9 октября 1992 г., Меморандум о сотрудничестве в области миграции от 8 июля 1994 г., Устав СНГ от 22 января 1993 г., Конвенция СНГ о правах и основных свободах человека от 26 мая 1995 г. и ряд других.

Однако, несмотря на солидную правовую базу и наличие институционального механизма в рамках СНГ, региональная система сотрудничества между странами СНГ функционирует не в полной мере, что, естественно, негативно отражается на положении беженцев и вынужденных переселенцев. В чем же дело? Проблема заключается в том, что, во-первых, отсутствует региональный документ по беженцам, который охватывал бы все правовые аспекты данной проблемы и все государства региона; во-вторых, в структуре СНГ нет органа, подобного УВКБ ООН, который бы обеспечивал предоставление помощи на региональном уровне вообще.и координировал международное сотрудничество в частности.

\footnotetext{
${ }^{13}$ Подробнее см.: Беженцы и вынужденные переселенцы в государствах СНГ / Под ред. В. Мукомеля и Э. Паина. М., 1995. С. 31-34.
} 
Поэтому для активизации регионального сотрудничества в регионе необходимо:

a) создать межгосударственный орган СНГ, который специализируется исключительно на решении проблем беженцев и вынужденных переселенцев и обладает компетенцией, подобной компетенции УВКБ $\mathrm{OOH}$; необходимо предусмотреть контрольные функции этого органа за выполнением положений универсальных и региональных соглашений, касающихся указанных категорий лиц, а также широкую международную правоспособность и ответственность этого органа ${ }^{14}$; очень важно, чтобы этот орган осушествлял сотрудничество не только с государствами СНГ, но также с другими структурами Содружества (например, Комиссией по правам человека СНГ), занимающимися гуманитарными вопросами, и другими региональными системами сотрудничества;

б) разработать и принять всеобъемлющий региональный документ - Конвенцию СНГ о статусе беженцев и вынужденных переселенцев, которая будет учитывать достижения международного права на универсальном и региональном уровнях, а таюже потребности и особенности данной проблемы в регионе СНГ.

Большое значение для развития региональной системы международного сотрудничества СНГ в отношении беженцев играет проведение региональных конференций с участием как государств региона, так и других государств, международных и неправительственных организаций. Это необходимо для обмена опытом и выработки единого подхода к решению этой сложной проблемы.

Положительным примером этого вида сотрудничества является состоявшаяся 30-31 мая 1996 г. в Женеве Региональная конференция для рассмотрения проблем беженцев, перемешенньк лиц, других форм недобровольного переселения и репатриантов в странах СНГ и в соответствующих соседних государствах (далее Конференция по странам $\mathrm{CH} \Gamma$ ).

Еще в 1994 г., признавая потенциальную опасность неконтролируемых массовых перемещений населения на территории бывшего СССР, Генеральная ассамблея ООН в своей резолюции 49/173 призвала УВКБ ООН созвать вышеуказанную конференцию.

\footnotetext{
${ }^{14}$ По аналогии этот межгосударственный орган может быть назван Управление Верховного комиссара СНГ по делам беженцев и вынужденных переселенцев.
} 
В процессе подпотовки к Конференции предстояло решить три задачи:

1) обеспечить проведение представительного регионального форума для обсуждения проблем, связанных с перемещениями населения;

2) провести анализ всех движений населения в регионе с целью прояснения и согласования видов движения населения и категорий граждан, вовлеченных в эти движения;

3) разработать всестороннюю стратегию на национальном, региональном и международном уровнях.

Проведение самой Конференции по странам СНГ предваряли субрегиональные встречи государств, совещания экспертов, разработка проектов документов конференции ${ }^{15}$.

Делегаты из 87 стран, 34 международных организаций и 77 неправительственных организаций собрались в Женеве 30-31 мая 1996 г. Конференция была организована УВКБ ООН в тесном сотрудничестве с Международной организацией по миграции (МОМ) и Организацией по безопасности и сотрудничеству в Европе (ОБСЕ).

В результате двухлетней подготовительной работы и двухдневной работы Конференции по странам СНГ были рассмотрены важные вопросы, касающиеся проблемы перемешения населения, беженцев и других категорий вынужденных мигрантов. В итоге участники конференции приняли документ «Программа действий» ${ }^{16}$.

Этот объемный документ включает в себя следующие положения: Декларацию, главу I «Принципы» ${ }^{17}$, главу II «Институциональные рамки» ${ }^{18}$, главу III «Оперативные рамки» ${ }^{19}$, главу IV «Предупреждение» ${ }^{20}$, главу V «Сотрудничество», посвященную межправительственному

\footnotetext{
${ }^{15}$ Подробнее о работе Конференции по странам СНГ см.: Конференция СНГ по проблемам беженцев и мигрантов. Европейская серия. 1996. Т. 2. № 1, 2; Мессина К. Регулирование потоков беженцев и мигрантов // «Беженцы». 1996. №. 4 С. 18.; Положение беженцев в мире. 1997-1998. Перемещенные лица - гуманитарная проблема, УВКБ ООН. М.: «Интердиалекг+». 1997. С. 38-39.; Старушенко Г.Б. Соотечественники: правовой аспект проблемы // Московский журнал международного права. 1998. № 4. С. 214-215.

${ }^{16}$ Док. OOH, CISCONA, 1996/PA/4.

${ }^{17}$ Всего их 23. Касаются они основы, на которой взаимодействуют государства региона.

18 Здесь рассматриваются вопросы выработки политики, законодательства, а также административные вопросы.

19 Здесь высказаны рекомендации по оказанию чрезвычайной помощи, репатриации, возвращению и расселению вынужденных мигрантов, а также их интеграции.

${ }^{20} \mathrm{~B}$ этой главе Программы рассматриваются вопросы наблюдения и раннего оповещения в отношении ситуаций, вызывающих миграцию населения, меры по предупреждению подобных ситуачий, а также способы разрешения конфликтов.
} 
сотрудничеству между странами СНГ и другими заинтересованными странами, сотрудничеству с международными и неправительственными организациями; главу VI «Выполнение и последующие меры», два Приложения - «Список участников Подготовительного процесса» и «Рабочие определения».

Программа действий, в частности, предусматривает осуществление следующих мероприятии:

- обеспечение государствами на основании национальных законов предоставления гражданства всем лицам, являющимся гражданами государства-предшественника и в настоящее время постоянно проживающим на их территории (п. 15b);

- приведение в случае необходимости национального законодательства в соответствие с международным правом, касающимся прав человека, беженцев и гуманитарных аспектов (п. 101);

- создание поста омбудсмана по правам человека и др.

Необходимо отметить историческое значение данной конференции, которая стала первым шагом в формировании и развитии региональной системы сотрудничества СНГ по проблеме беженцев и вынужденных переселенцев. В своем докладе на конференции Руководитель Федеральной миграционной службы РФ Т.М. Регент сказала: «Для России сама конференция и налаживание межгосударственного взаимодействия на данном направлении входят в число приоритетных вопросов внешнеполитической деятельности» ${ }^{21}$. Конференция обозначила существующие проблемы и пути их решения. Очевидно, что нельзя ожидать быстрого и положительного результата. Слишком мало прошло времени. Необходимо учесть и факт ухудшения общей обстановки на территории государств - участников СНГ.

Большой интерес для исследования представляет региональная система сотрудничества, функционирующая в рамках ОБСЕ. Особенность этой системы заключается в том, что «процедуры ОБСЕ, возможно, не имеют строго нормативного характера, свойственного международному договору ${ }^{22}$. Вопрос о сотрудничестве государств в рамках ОБСЕ постоянно находится в центре внимания на каждой встрече ${ }^{23}$. Напри-

\footnotetext{
${ }^{21}$ Регент Т.М. Миграционный круговорот обездоленных (из выступления на Международной конференции по проблемам беженцев) // МЖМП. 1997. № 1, С. 118.

${ }^{22}$ Гай С. Гудвин-Гилл. Статус беженца в международном праве. М.: ЮНИТИ, 1997. C. 272 .

${ }^{23}$ Принцип сотрудничества между государствами ОБСЕ был зафиксирован еще в Заключительном акте СБСЕ, подписанном 35 государствами в 1975 г.
} 
мер, на Венской встрече 1986-1987 гг. государства-участники СБСЕ ${ }^{24}$ обсудили комплекс вопросов, касающихся миграции, включая свободу покидать любую страну, включая свою собственную, и возвращаться туда, а также право беженцев на репатриацию ${ }^{25}$.

В Заключительном документе Копенгагенской конференции СБСЕ по человеческому измерению также были подтверждены основные права человека, включая свободу передвижения и всеобъемлющее право на эффективные средства правовой защиты ${ }^{26}$. Позднее, в ноябре 1990 г., государства СБСЕ приняли Парижскую хартию для новой Европы с руководящими принципами укрепления демократических институтов, поощрения богатого вклада национальных меньшинств, борьбы против всех форм этнической розни и дискриминации и т.д. ${ }^{27}$

Отличительной особенностью данной системы регионального сотрудничества является то, что она объединяет не только государства Европы, но и государства Северной Америки (США и Канаду) и Средней Азии, приобретая, таким образом, интеррегиональный характер ${ }^{28}$.

Несмотря на тот факт, что процесс сотрудничества в рамках ОБСЕ носит во многом формальный, необязательный характер ${ }^{29}$, неоднократное подтверждение государствами-участниками основных принципов, а также формирование и развитие новых структур ОБСЕ - важное доказательство укрепления нормы о сотрудничестве и процесса все более широкого участия государств в этой региональной системе сотрудничества по вопросам защиты беженцев и других категорий вынужденных мигрантов.

${ }^{24} \mathrm{C} 1$ января 1995 г. Организация по безопасности и сотрудничеству в Евpone.

${ }^{25}$ Совещание по безопасности и сотрудничеству в Европе: Заключительный документ Венской встречи

(4 ноября 1986 г. - 17 января 1987 г.): 28 ILM 527 (1989). В Заключительном документе конкретно определялись общие принципы, включая права человека, свободу передвижения и репатриации применительно к беженцам; сотрудничество, в частности, по проблеме трудящихся-мигрантов; сотрудничество в гуманитарной и других областях, включая человеческие контакты и свободу отъезда и возвращения; и человеческое измерение: права человека, человеческие контакты и другие гуманитарные вопросы.

${ }^{26}$ Подробнее см.: СБСЕ: Документ Копенгагенской встречи Конференции по человеческому измерению, 29 июня 1990 г.: 29 ILM 1305 (1990).

${ }^{27}$ Подробнее см.: СБСЕ: Парижская хартия для новой Европы, 21 ноября 1990 г.: 30 ILM 190 (1991).

${ }_{28}^{28}$ По состоянию на 1 января 2001 г. в ОБСЕ входило 53 государства-участника.

${ }^{29}$ Процедуры и механизмы ОБСЕ начинают действовать при наличии трех условий: воли государств-участников к действию, принципиального консенсуса по поводу принятых решений, готовности к использованию согласованных механизмов ОБСЕ. 
Еще несколько лет назад СБСЕ была хорошим дополнением европейской системы сотрудничества по проблеме беженцев. Однако после преобразования в 1995 г. СБСЕ в ОБСЕ эту международную организацию следует рассматривать как независимую систему регионального сотрудничества, которая имеет сформировавшуюся структуру органов, при этом постоянно изменяющуюся ${ }^{30}$.

Помимо рассмотренных выше региональных систем сотрудничества, сушествуют и другие, которые не являются предметом исследования в данной работе.

Рассмотрев три региональные системы сотрудничества можно сделать следующие выводы:

1. Африканская региональная система сотрудничества по проблеме беженцев существует 35 лет, имеет уже сформировавшиеся системы институтов и международных соглашений, объединяет почти все государства региона, которые осуществляют постоянное и тесное сотрудничество по проблеме беженцев между собой, с другими региональными системами и с универсальной системой. В сравнения с другими региональными системами африканская носит прогрессивный характер (доказательство тому - расширительное толкование понятия «беженец»);

2. Региональная система СНГ сушествует 10 лет, не имеет сформировавшихся эффективных систем институтов и международных договоров, объединяет только $50 \%$ государств региона, которые в настоящее время не осуществляют постоянного и тесного сотрудничества по вопросам беженцев между собой ${ }^{31}$, с другими региональными системами и универсальной системой. В дополнение к этому использование концепции «вынужденного переселенца» явно не способствует применению единого подхода к понятию «беженец» ${ }^{32}$ и затрудняет

\footnotetext{
${ }^{30}$ Среди органов ОБСЕ, занимающихся правами человека и беженцами, следует отметить создание в 1992 г. поста Верховного комиссара по делам национальных меньшинств, а также Механизма по реализации обязательств ОБСЕ в области человеческого измерения.

${ }^{31}$ Автор полагает, что система сотрудничества в рамках СНГ носит субрегиональный характер, так как количество ее стран-участниц едва превышает 50\% государств региона.

${ }^{32}$ Несмотря на то, что в ходе Конференции по странам СНГ иностранные эксперты отрицательно высказались в отношении этой правовой категории, предложив не использовать ее в дальнейшем. Подробнее об зтом см.: Конференция СНГ по проблемам беженцев и мигрантов. Европейская серия. 1996. Т. 2. №. 1. С. 159-165.
} 
сотрудничество стран региона и других государств. Ее можно назвать субрегиональной системой сотрудничества, так как в ней участвуют несколько государств СНГ;

3. Региональная система сотрудничества в рамках ОБСЕ формально существует с 1975 г., но структурно оформилась лишь в 1995 г. Она обладает сформировавшимися системами институтов и международных соглашений, объединяет более 50 государств из различных регионов, вследствие чего приобретает интеррегиональный характер. Данная система активно функционирует как внутри себя, так и за своими пределами.

Однако, несмотря на все положительные и отрицательные черты, присущие всем трем региональным системам, им не удается эффективно решать проблему беженцев и других категорий лиц, вынужденных покинуть страну гражданской принадлежности или обычного местожительства.

Исходя из вышесказанного, автор заключает: несмотря на то, что региональные системы межгосударственного сотрудничества функционируют на основе универсальных международных соглашений в области защиты беженцев, они обладают отличительными особенностями, чертами, которые выражаются в расширительном толковании понятия «беженец» или, наоборот, использование различных правовых концепций (например, вынужденного переселенца) и институциональных механизмов и др.

Все это, с одной стороны, способствует прогрессивному и эффективному межгосударственному сотрудничеству стран, входящих в отдельную региональную систему, а с другой - создает помехи взаимодействию региональных систем сотрудничества между собой, а также с глобальной системой сотрудничества по вопросу беженцев и вынужденных мигрантов.

В настоящей статье были рассмотрены правовые и институциональные аспекты международного сотрудничества по проблеме беженцев на региональном и субрегиональном уровнях в институциональной форме в виде международных организаций. Рассмотренные нами региональные системы сотрудничества не действуют разрозненно, а являются одним из составных элементов глобальной системы международного сотрудничества по проблеме беженцев, которая включает в себя следуюшие элементы: 
1) систему двустороннего сотрудничества государств;

2) систему сотрудничества ОOH, осуществляемого в рамках универсальных межправительственных организаций системы ООН, прямо (УВКБ ООН, БАПОР) или косвенно (ВОЗ, МОТ, МПП, ФАО, ПРО$\mathrm{OH}$ и др.) занимаюшихся вопросами беженцев и осушествляюших сотрудничество между собой и с другими элементами системы сотрудничества по проблеме беженцев;

3) систему сотрудничества в рамках международных межправительственных организаций, не входящих в систему учреждений $\mathrm{OOH}$ (MOM);

4) систему сотрудничества в рамках международных и местных неправительственных организаций (МККК, «Международная амнистия», «Врачи без границ» и др.);

5) региональные системы сотрудничества государств (Африканский союз, ОАГ, Совет Европы, ОБСЕ, СНГ и др.), которые могут подразделяться внутри себя на субрегиональные $(\mathrm{CH \Gamma})^{33}$, т.е. объединяющие более двух государств отдельной региональной системы сотрудничества по проблеме беженцев, и интеррегиональные, объединяюцие государства различных регионов планеты.

Система международного сотрудничества функционирует на основе общепризнанных принципов и норм международного права как обычного, так и договорного характера, принятых на универсальном, региональном, субрегиональном, государственном уровнях. К документам, на основе которых функционирует система международного сотрудничества, необходимо отнести документы рекомендательного характера. К ним относятся документы, принятые в рамках работы универсальных и региональных организаций и конференций (например, резолюции и декларации ГА ООН, международных конференций и организаций).

Глобальная система международного сотрудничества по проблеме беженцев не является «стопроцентно» единой, а, наоборот, состоит из нескольких систем, порой не связанных между собой никакими международно-правовыми соглашениями, имеюшими свои отличительные черты и особенности, но при этом координирующих свою деятельность. Нельзя категорично утверждать, что системы сотрудничества не взаи-

\footnotetext{
${ }^{33}$ Автор считает, что СНГ де-юре - региональная система сотрудничества, де-факто субрегиональная, так как объединяет не все государства - участники СНГ в области сотрудничества по проблемам беженцев и вынужденных переселенцев.
} 
модействуют между собой и носят закрытый характер. Но, очевидно, что это одна из многочисленных причин малоэффективного сотрудничества по проблеме беженцев, что в свою очередь негативно отражается на общей ситуации с беженцами в мире.

С другой стороны, данное положение вещей - всего лишь один из этапов формирования глобальной системы международного сотрудничества по данной проблеме. Объединение всех вышеперечисленных систем сотрудничества в глобальную систему на основе универсальных международно-правовых соглашений не должно означать жесткого подчинения других систем или их уничтожения. Наоборот, сохранение и совершенствование потенциальных подсистем, входящих в единую систему, будет способствовать эффективному решению проблем беженцев на уровне подсистемы. Важен единый правовой подход к правовым аспектам международного сотрудничества.

Автор полагает, что государства, будучи главными участниками международных отношений и первичными субъектами международного права, должны стать инициаторами правового объединения всех систем сотрудничества в единую систему на основе целого комплекса универсальных соглашений, которые охватят своим действием все элементы системы и подчинят их одному международному органу, который будет создан государствами в рамках ООН со статусом специализированного учреждения. Государства должны осознать, ито для эффективного функционирования системы международного сотрудничества по проблеме беженцев они обязаны передать этому органу или организации (возможно, это будет Всемирная организация по вопросам беженцев) часть своих властных полномочий. Эта организация станет центральным и координирующим звеном эффективной системы международного сотрудничества по проблеме беженцев. Если этого не сделать, то проблема беженцев никогда не будет решена. 